\title{
Chemical composition and acaricidal activity of the essential oils from Vitex agnus-castus L. (Verbenaceae) and selected monoterpenes
}

\author{
ROBERTA C.S. NEVES and CLAUDIO A.G. DA CAMARA \\ Programa de Pós-Graduação em Química, Departamento de Química, Laboratório de Produtos Naturais Bioativos, \\ Universidade Federal Rural de Pernambuco, Av. Dom Manoel de Medeiros, s/n, 52171-900 Recife, PE, Brasil
}

Manuscript received on February 5, 2014; accepted for publication on March 11, 2016

\begin{abstract}
Tetranychus urticae is considered one of the main plagues in the world. Its occurrence in Pernambuco was registered for the first time in 1985 and it has caused considerable damage to the farmers, attacking different cultures of agricultural interest. The essential oils from different parts of Vitex agnus-castus harvested in the Atlantic forest in the state of Pernambuco, Brazil, were obtained by hydrodistillation and the acaricidal potential was evaluated against Tetranychus urticae using two methods under laboratory conditions. Gas chromatography-mass spectrometry revealed the presence of 47 components accounting for $98.8 \pm 0.0 \%$, $93.0 \pm 0.1 \%$ and $97.4 \pm 1.0 \%$ of the essential oils from the leaves, fruit and inflorescence, respectively. The compounds 1,8-cineole and $\beta$-(E)-farnesene were the major components of the oils from the leaves $(17.6 \pm$ $0.3 \%$ and $13.6 \pm 0.2 \%$, respectively) and fruit (17.5 $\pm 0.1 \%$ and $15.4 \pm 0.0 \%$, respectively). $\beta$-(E)-farnesene $(13.5 \pm 0.1 \%)$ and $\beta$-caryophyllene $(11.7 \pm 0.1 \%)$ were the major components of the oils from the flowers. Acaricidal action varied depending on the part of the plant and method employed. Through fumigation, the oil from the leaves $\left(\mathrm{CL}_{50}=0.61 \mu \mathrm{L} \mathrm{L}^{-1}\right.$ of air) was approximately six fold more toxic than the oil from the fruit. However, through residual contact, the oil from the fruit $\left(\mathrm{CL}_{50}=137.11 \mu \mathrm{LmL}^{-1}\right)$ was 1.1 fold more toxic than the oil from the leaves. The relationship between the chemical composition of the oils and acaricidal activity is also presented.
\end{abstract}

Key words: Acarcidal activity, Tetranychus urticae, 1,8-cineole, essential oil, Vitex agnus-castus.

\section{INTRODUCTION}

Vitex agnus-castus (Verbenacea) measures five to six meters in height and has leaves, fruit and inflorescences with a pleasant fragrance. The fruit is brown, with a slighting spicy aroma and flavor and is used in place of ground pepper in different parts of the world. This plant is native to Mediterranean Europe and central Asia and was brought to Brazil

Correspondence to: Claudio Augusto Gomes da Camara

E-mail: claudio_agc@hotmail.com during the Portuguese colonization, probably by Africans. It is used in Afro-Brazilian religious ceremonies in the northern and northeastern regions of Brazil and is grown as an ornamental plant for public squares and residential gardens. In regions where the plant is native, medicinal products are made from the fruit as a remedy for the symptoms of menopause (Daniele et al. 2005). In Brazil, its medicinal use is related to infusions made from the shoots and fruit for the treatment of stomachache, headache and syphilis (Matos 2002). 
Different parts of $V$. agnus-castus (leaves, fruit and flowers) contain essential oils, the chemical composition of which varies with the geographic origin. Previous investigations into the essential oils of this species collected in different regions of the world have found the major constituents to be 1,8-cineole, limonene, $\alpha$-pinene, sabinene, $\alpha$-terpineol, $\beta$-(E)-farnesene, $\alpha$-terpenil acetate, $\beta$-caryophyllene and bicyclogermancrene (Erygita et al. 2015, Novak et al. 2005). Due to the diverse biological properties of these chemical constituents, species of the genus are a rich source of bioactive compounds. Indeed, a number of biological properties of the extract or essential oil from $V$. agnus-castus have recently been reported, such as antimicrobial (Omikored et al. 2012, Stojkovic et al. 2011, Marongiu et al. 2010, Senatore et al. 2003), antimutagenic (Sarac et al. 2015), cytotoxic (Duymus et al. 2014), nematicidal (Ntalli et al. 2010), molluscicidal activities (Elgengaihi et al. 1992), antioxidant, anti-inflammatory and antiacetylcholinesterase (Miguel et al. 2014). Recently, Omikored et al. (2012) reported insecticidal activity for the oil from $V$. agnus-castus against pests found in grains, such as Acantohoscelides obtectus, Sitophilus zeamais and Tribolium castaneum. However, to the best of our knowledge, no studies have reported the acaricidal activity of the essential oils from $V$. agnus-castus against the two-spotted spider mite (Tetranychus urticae), which is an important agriculture pest throughout the world.

As part of an ongoing effort in the search for natural substances with acaricidal properties, the aim of the present study was to investigate essential oils from Vitex agnus-castus as a source of biologically active compounds with acaricidal activity. This study reports the chemical composition of essential oils from different organs of the $V$. agnus-castus (leaves, fruit and flowers) from a fragment of the Atlantic forest in the state of Pernambuco, northeastern Brazil, and the acaricidal activity against Tetranychus urticae of individual constituents and/or blends of the main constituents.

\section{MATERIALS AND METHODS}

\section{COLLECTION OF Plant MATERIAL}

Fresh leaves, fruit and flowers were collected in the morning period in September 2009 from a fragment of the Atlantic forest in the city of Recife, state of Pernambuco, Brazil. The plant was identified by Dr. Maria Rita Cabral Sales de Melo of the Biology Department of the Rural Federal University of Pernambuco through comparisons with previously identified samples and deposited at the Vasconcelos Sobrinho Herbarium of the university (accession number: 48489).

\section{ISOLATION OF ESSENTIAL OILS}

Essential oils were extracted from fresh leaves, fruit and flowers of $V$. agnus-castus (100 g) using a modified Clevenger-type apparatus and hydrodistillation for $2 \mathrm{~h}$. The oil was separated and dried over anhydrous sodium sulfate, stored in hermetically sealed glass containers and kept under refrigeration at $5{ }^{\circ} \mathrm{C}$ until analysis and the acaricidal assays. Total oil yield was expressed as a percentage value ( $\mathrm{g} / 100 \mathrm{~g}$ of fresh plant material). All experiments were carried out in triplicate.

\section{CHEMICALS}

The monoterpenes and sesquiterpenes used in the identification of volatile components and acaricidal assays ( $\alpha$-pinene, $\beta$-pinene, 1,8 -cineole, terpinen4-ol, $\alpha$-terpineol and $\beta$-caryophyllene) and eugenol used in the bioassays as the positive control were purchased from Sigma-Aldrich (Brazil).

\section{OPTICAL ROTATION}

Optical rotation of the essential oils was performed with a digital polarimeter (A. Krüss model Px800, Germany) at $589 \mathrm{~nm}$ and $26^{\circ} \mathrm{C}$ in a dichloromethane solution. 
CHEMICAL ANALYSIS AND IDENTIFICATION OF OIL COMPONENTS

The oils from $V$. agnus-castus were analyzed using gas chromatography (GC-FID) and chromatography-mass spectrometry (GC-MS) and identification of the components was performed using the same methodology described in previous reports by our research team (Moraes et al. 2012, Araújo et al. 2012). The identification of the components was based on the GC-FID retention indices with reference to a homologous series of $\mathrm{C}_{11}-\mathrm{C}_{24}$ n-alkanes and by computer matching against the mass spectral library of the GC-MS data system (NIST 98 and Willey) and co-injection with authentic standards (Adams 2007).

ACARICIDAL ASSAYS

Specimens of $T$. urticae used for the bioassays were reared on jack bean (Canavalia ensiformes L.) without any exposure to acaricidal agents at the Agronomy Department of the Rural Federal University of Pernambuco, Brazil. All bioassays were performed at a temperature of $25 \pm 1{ }^{\circ} \mathrm{C}$, with relative humidity of $65 \pm 5 \%$ and a 12 -h photoperiod.

FUMIGANT AND RESIDUAL ASSAYS

The fumigant and residual effect methods were the same as those employed by Araújo et al. (2012). The mortality data for $V$. agnus-castus oil and eugenol were analyzed with the Probit model using the POLO-PC software program (LeOra 1987) for the determination of the lethal concentration necessary for $50 \%$ mortality $\left(\mathrm{LC}_{50}\right)$ of the mite population, with the calculation of $95 \%$ confidence levels. Toxicity ratios were determined based on the method described by Robertson and Preisler (1992). The data were submitted to analysis of variance (ANOVA) and means were compared using Tukey's test, with the level of significance set to $5 \%(p<0.05)$. In the fumigant assays, the concentrations ranged from $8 \times 10^{-3}$ to $15 \mu \mathrm{L} \mathrm{L}^{-1}$ of air for the oils and $3.2 \times 10^{-4}$ to $16 \mu \mathrm{L} \mathrm{L}^{-1}$ of air for the constituents. In the residual assays, concentrations ranged from 1 to $400 \mu \mathrm{L} \mathrm{mL}^{-1}$ for the oils and 0.1 to $475 \mu \mathrm{L} \mathrm{mL}^{-1}$ for the constituents. The results were submitted to statistical descriptive analysis using the Statistical Analysis System Software (SAS Institute 2002).

\section{COMPARATIVE TOXICITY OF COMPOUNDS}

To investigate the role of terpenoides and the toxicity of the essential oils from $V$. agnus-castus, commercially available natural compounds $(\alpha$-pinene, $\beta$-pinene, 1,8-cineole, terpinen-4-ol, $\alpha$-terpineol, and $\beta$-caryophyllene) representing $53.5 \%$ of the leaf oil and $46.1 \%$ of the fruit oil were selected. The fumigant activity and residual effects of these compounds were evaluated both individually and in the form of blends at the same proportion found in the oils, as identified by GC-MS. The toxicity of these compounds was evaluated at the same concentration of $V$. agnuscastus oil that promoted $>95.0 \%$ mortality (for fumigation: $12 \mu \mathrm{L} \mathrm{L}^{-1}$ of air; for residual effect: 350 $\mu \mathrm{L} / \mathrm{mL}$ and $15 \mu \mathrm{L} \mathrm{L}^{-1}$ of air for leaf oil and $400 \mu \mathrm{L} /$ $\mathrm{mL}$ for fruit oil). A complete blend of the selected constituents was first prepared from the oil. For the selected constitutes, further blends were prepared to identify the contribution of each compound to the toxicity of the entire mixture.

\section{RESULTS AND DISCUSSION}

Hydrodistillation of the leaves, fruit and flowers of Vitex agnus-castus L. led to oils of a yellowish color and pleasant aroma. Table I displays the yields of the oils from the leaves and fruit of V.agnus-castus, which were in agreement with yields reported for other samples collected in Brazil (Zoghbi et al. 1999). GC-MS allowed the identification of 47 compounds in the oils, representing $98.8 \pm 0.0 \%$ 
of the oil from the leaves, $93.0 \pm 0.1 \%$ of the oil from the fruit and $97.4 \pm 1.0 \%$ of the oil from the flowers. Table I displays the volatile components identified in the oils in the elution order in the DB-5 column.
The optical rotation of the oils was levorotatory, with large angles for the oils from the fruit $\left([\alpha] \mathrm{D}_{22}\right.$ $\left.=-15.6^{\circ}, \mathrm{c} .=1, \mathrm{CH}_{2} \mathrm{Cl}_{2}\right)$ and flowers $\left([\alpha] \mathrm{D}_{22}=\right.$ $-20.3^{\circ}$, c. $=1, \mathrm{CH}_{2} \mathrm{Cl}_{2}$ ) and small angles for the oil from the leaves $\left([\alpha] \mathrm{D}_{22}=-5.9^{\circ}, \mathrm{c} .=1, \mathrm{CH}_{2} \mathrm{Cl}_{2}\right)$.

TABLE I

Percentage composition, yield and optical rotation of leaf, fruits and inflorescence essential oils from $V$. agnus-castus.

\begin{tabular}{|c|c|c|c|c|c|c|}
\hline $\begin{array}{c}\text { Compound } \\
\text { Yield }(\%) \pm \mathrm{SD} \\
{[\alpha]_{22}^{\mathrm{D}}\left(\mathrm{c}=1, \mathrm{CH}_{2} \mathrm{Cl}_{2}\right)}\end{array}$ & $\mathbf{R I}^{\mathbf{a}}$ & $\mathbf{R I}^{\mathrm{b}}$ & $\begin{array}{c}\text { Leaf } \\
0.22 \\
-29.3^{\circ} \\
\end{array}$ & $\begin{array}{c}\text { Fruit } \\
0.13 \\
-15.6^{\circ}\end{array}$ & $\begin{array}{c}\text { Flower } \\
0.07 \\
-5.9^{\circ}\end{array}$ & Method of identification \\
\hline$\alpha$-pinene & 941 & 932 & $2.3 \pm 0.1$ & - & - & RI, MS, CI \\
\hline$\beta$-pinene & 975 & 974 & $5.6 \pm 0.1$ & $1.0 \pm 0.1$ & $0.1 \pm 0.0$ & RI, MS, CI \\
\hline myrcene & 992 & 988 & $2.1 \pm 0.0$ & $0.6 \pm 0.0$ & - & RI, MS \\
\hline$\alpha$-phellandrene & 1010 & 1002 & $0.8 \pm 0.0$ & - & - & RI, MS \\
\hline 1,8-cineole & 1035 & 1026 & $17.6 \pm 0.3$ & $17.5 \pm 0.1$ & $1.5 \pm 0.0$ & RI, MS, CI \\
\hline$\beta$-(E)-ocimene & 1047 & 1044 & $1.1 \pm 0.0$ & $0.5 \pm 0.0$ & - & RI, MS \\
\hline$\gamma$-terpinene & 1065 & 1054 & $1.6 \pm 0.0$ & $1.1 \pm 0.0$ & - & RI, MS \\
\hline$p$-mentha-2(4),8-diene & 1093 & 1085 & $0.2 \pm 0.0$ & - & - & RI, MS \\
\hline linalool & 1099 & 1095 & - & - & $3.4 \pm 0.0$ & RI, MS \\
\hline trans-hidrate-sabinene & 1100 & 1098 & - & $1.9 \pm 0.0$ & - & RI, MS \\
\hline$c i s$ - $p$-menth-2-en-1-ol & 1122 & 1118 & $0.5 \pm 0.0$ & $0.7 \pm 0.0$ & $0.6 \pm 0.0$ & RI, MS \\
\hline trans-p-menth-2-en-1-ol & 1138 & 1136 & - & $0.3 \pm 0.0$ & $0.4 \pm 0.1$ & RI, MS \\
\hline$\delta$-terpineol & 1167 & 1162 & $2.0 \pm 0.0$ & $3.5 \pm 0.0$ & $1.0 \pm 0.0$ & RI, MS \\
\hline terpinen-4-ol & 1178 & 1174 & $5.2 \pm 0.0$ & $5.4 \pm 0.0$ & $7.5 \pm 0.0$ & RI, MS,CI \\
\hline$\alpha$-terpineol & 1193 & 1186 & $7.4 \pm 0.0$ & $5.2 \pm 0.0$ & $4.6 \pm 0.0$ & RI, MS,CI \\
\hline trans-piperitol & 1206 & 1207 & - & - & $0.4 \pm 0.0$ & RI, MS \\
\hline citronellol & 1226 & 1223 & - & - & $0.8 \pm 0.0$ & RI, MS \\
\hline nerol & 1228 & 1227 & $0.1 \pm 0.0$ & $0.4 \pm 0.0$ & - & RI, MS \\
\hline geraniol & 1252 & 1249 & - & - & $0.8 \pm 0.0$ & RI,MS \\
\hline$\delta$-terpinyl acetate & 1315 & 1316 & - & $0.7 \pm 0.0$ & - & RI, MS \\
\hline cis-piperitol acetate & 1338 & 1332 & - & - & $0.9 \pm 0.0$ & RI,MS \\
\hline$\alpha$-terpinyl acetate & 1353 & 1346 & $8.3 \pm 0.0$ & $11.9 \pm 0.1$ & $8.5 \pm 0.0$ & RI, MS \\
\hline neo-iso-deidro carveol acetate & 1361 & 1356 & - & $0.6 \pm 0.0$ & $1.4 \pm 0.0$ & RI, MS \\
\hline (E)-methyl cinnamate & 1377 & 1376 & - & - & $0.5 \pm 0.0$ & RI,MS \\
\hline 7-epi-sesquitujene & 1391 & 1390 & - & - & $0.1 \pm 0.0$ & RI,MS \\
\hline$\alpha$-gurjunene & 1413 & 1409 & $0.8 \pm 0.0$ & $0.7 \pm 0.0$ & $1.1 \pm 0.0$ & RI, MS \\
\hline$\beta$-caryophyllene & 1425 & 1421 & $9.4 \pm 0.0$ & $6.1 \pm 0.0$ & $11.7 \pm 0.1$ & $\mathrm{RI}, \mathrm{MS}, \mathrm{CI}$ \\
\hline$\alpha$-trans-bergamotene & 1438 & 1432 & $0.5 \pm 0.0$ & $0.4 \pm 0.0$ & $2.2 \pm 0.1$ & RI, MS \\
\hline (Z)-farnesene & 1445 & 1442 & $1.3 \pm 0.0$ & $1.2 \pm 0.0$ & $4.8 \pm 0.1$ & RI, MS \\
\hline$\beta$-(E)-farnesene & 1466 & 1454 & $13.6 \pm 0.2$ & $15.4 \pm 0.0$ & $13.5 \pm 0.1$ & RI, MS \\
\hline isodaucene & 1504 & 1500 & $8.9 \pm 0.0$ & $7.3 \pm 0.0$ & $6.9 \pm 0.1$ & RI, MS \\
\hline$\gamma$-cadinene & 1516 & 1513 & - & $0.4 \pm 0.0$ & - & RI, MS \\
\hline$\beta$-sesquiphellandrene & 1525 & 1521 & - & $0.7 \pm 0.0$ & $2.3 \pm 0.1$ & RI, MS \\
\hline$\delta$-cadinene & 1530 & 1522 & $0.6 \pm 0.0$ & - & - & RI, MS \\
\hline (E)-nerolidol & 1564 & 1563 & - & $0.3 \pm 0.0$ & $0.6 \pm 0.1$ & RI, MS \\
\hline palustrol & 1570 & 1568 & $0.3 \pm 0.0$ & $0.3 \pm 0.0$ & $1.1 \pm 0.0$ & RI, MS \\
\hline
\end{tabular}


TABLE I (continuation)

\begin{tabular}{|c|c|c|c|c|c|c|}
\hline Compound & $\mathbf{R I}^{\mathbf{a}}$ & $\mathbf{R I}^{\mathbf{b}}$ & Leaf & Fruit & Flower & Method of identification \\
\hline Yield $(\%) \pm$ SD & & & 0.22 & 0.13 & 0.07 & \\
\hline$[\alpha]_{22}^{\mathrm{D}}\left(\mathrm{c}=1, \mathrm{CH}_{2} \mathrm{Cl}_{2}\right)$ & & & $-29.3^{\circ}$ & $-15.6^{\circ}$ & $-5.9^{\circ}$ & \\
\hline spathulenol & 1579 & 1577 & $0.0 \pm 0.0$ & $0.5 \pm 0.0$ & $6.4 \pm 0.0$ & RI, MS \\
\hline tyujopsan-2- $\alpha-$ ol & 1586 & 1586 & - & $0.4 \pm 0.0$ & - & RI, MS \\
\hline globulol & 1592 & 1590 & $1.2 \pm 0.0$ & - & - & RI, MS \\
\hline viridiflorol & 1594 & 1592 & - & - & $1.6 \pm 0.1$ & RI, MS \\
\hline ledol & 1605 & 1602 & $1.4 \pm 0.0$ & $0.9 \pm 0.0$ & $2.1 \pm 0.0$ & RI, MS \\
\hline dill apiole & 1631 & 1620 & - & $1.0 \pm 0.0$ & - & RI, MS \\
\hline$\alpha$-muurolol & 1645 & 1644 & $2.9 \pm 0.0$ & $3.9 \pm 0.1$ & $6.8 \pm 0.1$ & RI, MS \\
\hline$\alpha$-cadinol & 1656 & 1652 & $0.2 \pm 0.0$ & $0.4 \pm 0.0$ & $1.1 \pm 0.0$ & RI, MS \\
\hline$\beta$-epi-bisabolol & 1671 & 1670 & - & - & $1.0 \pm 0.0$ & RI, MS \\
\hline$\alpha$-bisabolol & 1684 & 1685 & $0.5 \pm 0.0$ & $0.3 \pm 0.0$ & $1.7 \pm 0.1$ & RI, MS \\
\hline 13-epi-dolabradiene & 1990 & 2000 & $1.8 \pm 0.0$ & $1.5 \pm 0.0$ & - & RI, MS \\
\hline Phenylpropanoids & & & - & $1.0 \pm 0.0$ & $10.8 \pm 0.1$ & \\
\hline Monoterpenes & & & $55.3 \pm 0.3$ & $51.3 \pm 0.1$ & $21.7 \pm 0.0$ & \\
\hline Sesquiterpenes & & & $41.6 \pm 0.3$ & $39.1 \pm 0.1$ & $58.1 \pm 1.0$ & \\
\hline Diterpenes & & & $1.8 \pm 0.0$ & $1.5 \pm 0.0$ & - & \\
\hline Total & & & $98.8 \pm 0.0$ & $93.0 \pm 0.1$ & $97.4 \pm 1.0$ & \\
\hline
\end{tabular}

${ }^{a}$ Retention indices calculated from retention times in relation to those of the series n-alkanes on a $30 \mathrm{~m}$ DB-5 capillary column. ${ }^{b}$ Linear retention indices from the literature. $\mathrm{RI}=$ retention index, $\mathrm{MS}=$ mass spectrum, $\mathrm{CI}=$ co-injection with authentic standards.

The oil from the fruit exhibited greater chemical diversity in comparison to the oils from the leaves and flowers. The fruit oil was characterized by monoterpenes, sesquiterpenes, diterpenes and phenylpropanoids, whereas no phenylpropanoids or diterpenes were found in the oils of the leaves and flowers, respectively. Phenylpropanoids and diterpenes were only represented by dill apiole $(1.0 \pm 0.0 \%$ in the fruit) and 13-epi-dolabradiene $(1.8 \pm 0.0 \%$ in the leaves and $1.5 \pm 0.0 \%$ in the fruit). Monoterpenes constituted the predominant chemical class in the oils from the leaves and fruit, whereas, sesquiterpenes constituted the predominant class in the oil from the flowers (Table I). The compounds 1,8-cineole and $\beta$-(E)farnesene were the major constituents in the oils from the leaves $(17.6 \pm 0.3 \%$ and $13.6 \pm 0.2 \%$, respectively) and fruit $(17.5 \pm 0.1 \%$ and 15.4 $\pm 0.0 \%$, respectively). The compounds $\beta$-(E)farnesene $(13.5 \pm 0.1 \%)$ and $\beta$-caryophyllene (11.7 $\pm 0.1 \%$ ) were the major constituents of the oil from the flowers (Figure 1).
The main component in the oils from the leaves and fruit (1,8-cineole) accounted for only $1.5 \pm 0.0 \%$ of the oil from the flowers.

Significant percentages of other compounds were also identified, such as isodaucene $(8.9 \pm$ $0.0 \%$ in the leaves, $7.3 \pm 0.0 \%$ in the fruit and 6.9 $\pm 0.1 \%$ in the flowers), $\alpha$-terpinyl acetate $(8.3 \pm$ $0.0 \%$ in the leaves, $11.9 \pm 0.1 \%$ in the fruit and $8.5 \pm 0.0 \%$ in the flowers $), \alpha$-terpineol $(7.4 \pm 0.0 \%$ in the leaves, $5.2 \pm 0.0 \%$ in the fruit and $4.6 \pm 0.0$ in the flowers), terpinen-4-ol $(5.2 \pm 0.0 \%$ in the leaves, $5.4 \pm 0.0 \%$ in the fruit and $7.5 \pm 0.0 \%$ in the flowers), $\beta$-pinene $(5.6 \pm 0.1 \%$ in the leaves, $1.0 \pm$ $0.1 \%$ in the fruit and $0.1 \pm 0.0 \%$ in the flowers), spathulenol $(0.0 \pm 0.0 \%$ in the leaves, $0.5 \pm 0.0 \%$ in the fruit and $6.4 \pm 0.0 \%$ in the flowers) and $\alpha$-muurolol ( $2.9 \pm 0.0 \%$ in the leaves, $3.9 \pm 0.1 \%$ in the fruit and $6.8 \pm 0.1 \%$ in the flowers).

In the literature, the essential oil from the fruit of the plant has been the most widely investigated with regard to chemical composition, followed by the flowers and leaves. According to Zoghbi et al. 


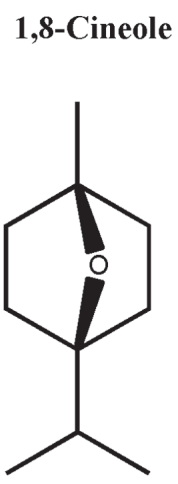

Leaves: $17.6 \pm 0.3 \%$

Fruits: $17.5 \pm 0.1 \%$

Flowers:

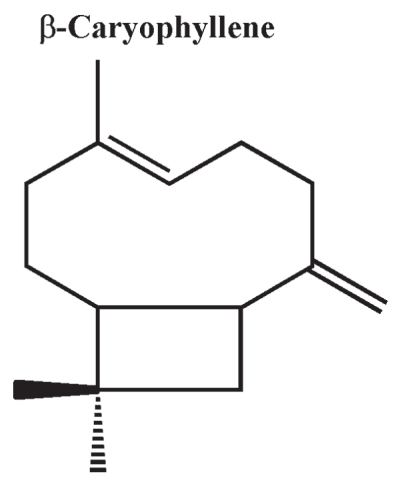

$$
\begin{aligned}
& 13.6 \pm 0.2 \% \\
& 15.4 \pm 0.0 \% \\
& 13.5 \pm 0.1 \%
\end{aligned}
$$

Figure 1 - Structures of main constituents identified in different parts of Vitex agnus-castus essential oils.

(1999), the main component found in the essential oil from the fruit of a sample collected in Brazil was $\beta$-(E)-farnesene $(23.1 \%)$. In the present analysis, $\beta$-(E)-farnesene was the main component in the flowers $(13.5 \pm 0.1 \%)$ and second most abundant component in the leaves $(13.6 \pm 0.2 \%)$ and fruit $(15.4 \pm 0.0 \%)$. Outside Brazil, investigations of the essential oil from the flowers have reveled other chemotypes, such as bicyclogermacrene $(9.7 \%)$ in Italy (Marongiu et al. 2010) as well as sabinene (17.56\%) and $\alpha$-terpineol (10.84 to $13.24 \%$ ) in different parts of Croatia (Males et al. 1998).

The main chemotype in the leaves and fruit of $V$. agnus-castus is reported to be 1,8-cineole, followed by sabinene. This chemotype has been identified in samples collected in Brazil (leaves) (Zoghbi et al. 1999), Spain (leaves and fruit) (Novak et al. 2005), Benin (leaves) (Moudachirou et al. 1998), Montenegro (leaves and fruit) (Stojkovic et al. 2011), Italy (leaves and fruit) (Senatore et al. 1996), Greece (fruit) (Sarikurkcu et al. 2009) and Turkey (fruit) (Sorensen and Katsiotis 1999, Senatore et al. 2003). Investigating the essential oil from leaves collected in Italy, Marongiu et al. (2010) found bicyclogermacrene (16.2\%), followed by $\beta$-(E)-farnesene (10.1\%).

Sabinene was absent from the present analyses, but is reported to be the main component in oils from leaves collected in Italy (Galletti et al. 1996), fruit collect in Greece (Sorensen and Katsiotis 1999) and flowers collected in Croatia (Males et al.1998) as well as the second most abundant component in samples collected in Brazil (Zoghbi et al. 1999), Spain (Novak et al. 2005) and Benin (Moudachirou et al. 1998). In the present study, trans-sabinene hydrate $(1.9 \pm 0.0 \%)$ was found only in the fruit, which was probably an artifact obtained through the oxidation of sabinene caused by the extraction process employed.

$\alpha$-Pinene is another monoterpene that has been found in significant amounts in samples collected in Brazil (8.9\%) (Zoghbi et al. 1999), Spain (16.4\%) (Novak et al. 2005), Montenegro (9.4\%) (Stojkovic et al. 2011), Nigeria (9.1\%) (Hamid et al. 2010) and Italy (7.6\%) (Senatore et al. 1996). However, $\alpha$-pinene was only found in the leaves in the present study, accounting for $\leq 2.3 \%$ of the oil.

Terpenoids with a greater molecular weight, such as diterpenes, have been found in different parts of the plant at amounts ranging from 7.9 to $0.1 \%$ in samples collected in Spain (Novak et al. 2005), Brazil (Zoghbi et al. 1999) and Italy (Marongiu et al. 2010, Galletti et al. 1996, Senatore et al.1996). The most common diterpene in $V$. agnus-castus is reported to be manool and its derivatives. However, the diterpene 13-epi-dolabradiene is reported herein 
for the first time in the oil from the leaves and fruit of V. agnus-castus, at amounts less than $2 \%$.

In the present investigation of the chemical components of essential oils from $V$. agnus-castus collected from a fragment of the Atlantic forest in the state of Pernambuco, Brazil, the composition varied depending on the part of the plant studied. $\beta$-(E)-farnesene identified in the leaves and flowers in the present analyses, and 1,8-cineole (leaves and fruit) have also been reported in samples collected in northern Brazil (Zoghbi et al. 1999). In both studies, the essential oils from the leaves and fruit was characterized by a high percentage of 1,8-cineole and the amount of $\beta$-(E)-farnesene identified in the leaves was the same.

Due to the low yield of essential oil from the flowers of $V$. agnus-castus, the acaricidal assays were employed only with the oils from the fruit and leaves. These oils demonstrated significant acaricidal activity against $T$. urticae. Toxicity was greater through fumigation in comparison to residual contact. Based on the mean $\mathrm{CL}_{50}$ values, toxicity varied with the different methods and parts of the plant investigated. Through fumigation, the oil from the leaves $\left(\mathrm{CL}_{50}=0.61 \mu \mathrm{L} \mathrm{L}^{-1}\right.$ of air) was approximately six fold more toxic than the oil from the fruit $\left(\mathrm{CL}_{50}=3.69 \mu \mathrm{L} \mathrm{L}^{-1}\right.$ of air). However, through residual contact, the oil from the fruit $\left(\mathrm{CL}_{50}=137.11 \mu \mathrm{L} \mathrm{mL}^{-1}\right)$ was 1.1 fold more toxic than the oil from the leaves $\left(\mathrm{CL}_{50}=160.48\right.$ $\left.\mu \mathrm{L} \mathrm{mL}{ }^{-1}\right)$. Comparing the results with the positive control, toxicity through fumigation with eugenol $\left(\mathrm{CL}_{50}=4 \times 10^{-3} \mu \mathrm{L} \mathrm{L}^{-1}\right.$ of air) was 100 fold greater in comparison to the oils from the leaves and fruit and toxicity through residual contact was 91 and 77.9 fold greater in comparison to the oils from the leaves and fruit, respectively (Table II).

The findings regarding the number of eggs laid by the two-spotted spider mite in the two experiments suggest that exposure to the oils does not inhibit oviposition, but causes a drastic reduction in fecundity. The literature also reports the ability of essential oils to reduce the quantity of mite eggs (Pontes et al. 2007a, b). In the present fumigation experiments, the number of eggs laid diminished significantly in comparison to the

TABLE II

Toxicity by Fumigation $\left(\mathrm{LC}_{50}\right.$ at $\mu \mathrm{L} \mathrm{L}^{-1}$ of air) and residual contact $\left(\mathrm{LC}_{50}\right.$ at $\left.\mu \mathrm{L} \mathrm{mL} \mathrm{m}^{-1}\right)$ of $V$. agnuscastus oils against Tetranychus urticae.

\begin{tabular}{|c|c|c|c|c|c|c|}
\hline Oil & $\mathbf{n}$ & df & Slope & $\begin{array}{c}\text { Fumigation } \\
\text { (CI 95\%) }\end{array}$ & $\chi^{2}$ & $\begin{array}{c}\mathrm{TR}_{50} \\
(\mathrm{CI} 95 \%)\end{array}$ \\
\hline Leaf & 720 & 5 & $\begin{array}{c}1.30 \\
(1.21-1.39)\end{array}$ & $\begin{array}{c}0.61 \\
(0.38-0.92)\end{array}$ & 8.48 & $\begin{array}{c}0.07 \\
(0.02-0.18)\end{array}$ \\
\hline Fruit & 720 & 4 & $\begin{array}{c}3.25 \\
(2.98-3.51)\end{array}$ & $\begin{array}{c}3,69 \\
(3.30-4.09)\end{array}$ & 1.35 & $\begin{array}{c}0.42 \\
(0.14-1.19)\end{array}$ \\
\hline \multirow[t]{2}{*}{$\mathbf{E U}$} & 540 & 5 & $\begin{array}{c}0.85 \\
(0.77-0.92) \\
\end{array}$ & $\begin{array}{c}0.004 \\
(0.002-0.005)\end{array}$ & 1.52 & - \\
\hline & & & & $\begin{array}{c}\text { Contact } \\
\text { (CI 95\%) }\end{array}$ & & - \\
\hline Leaf & 175 & 4 & $\begin{array}{c}2.45 \\
(2.10-2.81)\end{array}$ & $\begin{array}{c}160.48 \\
(101.25-271.67)\end{array}$ & 7.02 & $\begin{array}{c}18.68 \\
(10.38-33.64)\end{array}$ \\
\hline Fruit & 175 & 4 & $\begin{array}{c}2.81 \\
(2.45-3.17)\end{array}$ & $\begin{array}{c}137.11 \\
(96.16-193.35)\end{array}$ & 4.85 & $\begin{array}{c}15.78 \\
(7.24-34.36)\end{array}$ \\
\hline $\mathbf{E U}$ & 174 & 5 & $\begin{array}{c}2.16 \\
(1.85-2.47) \\
\end{array}$ & $\begin{array}{c}1.76 \\
(1.22-2.46) \\
\end{array}$ & 5.59 & - \\
\hline
\end{tabular}

$\mathrm{EU}=$ Eugenol as positive control. $\mathrm{n}=$ number of mites/dose; $\mathrm{df}=$ degrees of freedom. $\mathrm{CI}=$ confidence interval; $\chi^{2}=$ chi-squared; $\mathrm{TR}=$ toxicity ratio. 
control. The lowest concentration to achieve a significant reduction in oviposition was $0.08 \mu \mathrm{L}$ $\mathrm{L}^{-1}$ of air. These data regard the number of eggs laid by the population of mites and not the number of eggs per female. To confirm the deterrence of oviposition, new fumigation experiments were performed with the concentration of $0.08 \mu \mathrm{L} \mathrm{L}^{-1}$ of air. The results of the new test revealed that the mean numbers of eggs laid by mites exposed to essential oils from the leaves $(2.66 \pm 0.05)$ and fruit $(4.62 \pm 0.50)$ differed significantly from the controls $[2.29 \pm 0.12(F=7.14 ; \mathrm{gl}=10 ; p>0.0156)$ and $5.62 \pm 0.30(F=2.83 ; \mathrm{gl}=10 ; p>0.0195)$, respectively]. These data corroborate the results of the fumigation experiments and suggest that vapor from the essential oils of $V$. agnus-castus serves as a deterrent to oviposition.

The findings with both methods employed to test the toxicity of the essential oils of $V$. agnuscastus to T. urticae demonstrate that the type of bioassay exerted an influence on the susceptibility of the mites. Factors such as mode of action (vapor or contact and ingestion) and/or means of application (fumigation or residual contact) led to different degrees of susceptibility, suggesting that the oils have greater acaricidal activity when vapors penetrate the respiratory system (fumigation) than when ingested or absorbed through the tarsi (residual contact).

Five monoterpenes and one sesquiterpene were selected to investigate the role of the main chemical components identified in the oils with regard to acaricidal activity, with evaluations of the toxicity of the individual components and in the form of blends. The constituents selected and their respective relative percentages (identified through GC-MS) were $\beta$-pinene (5.6 $\pm 0.1 \%$ in the leaves), terpinen-4-ol $(5.2 \pm 0.0 \%$ in the leaves and $5.4 \pm$ $0.0 \%$ in the fruit), 1,8 -cineole $(17.6 \pm 0.3 \%$ in the leaves and $17.5 \pm 0.1 \%$ in the fruit), $\alpha$-terpineol (7.4 $\pm 0.0 \%$ in the leaves and $5.2 \pm 0.0 \%$ in the fruit), $\alpha$-terpinyl acetate $(8.3 \pm 0.0 \%$ in the leaves and
$11.9 \pm 0.1 \%$ in the fruit) and $\beta$-caryophyllene (9.4 $\pm 0.0 \%$ in the leaves and $6.1 \pm 0.0 \%$ in the fruit). As observed with the oils, toxicity of the selected compounds was greater through fumigation than residual contact. With the exception of $\beta$-caryophyllene, toxicity of the constituents varied with the method employed. Based on the mean $\mathrm{CL}_{50}$ values of the selected compounds, the order of toxicity through fumigation was $\beta$-caryophyllene $>$ terpinen-4-ol $=\alpha$-terpinyl acetate $>\alpha$-terpineol $>\beta$-pinene $=1,8$-cineole and the order through residual contact was $\beta$-caryophyllene $>\beta$-pinene $=\alpha$-terpineol $>1,8$-cineole $>\alpha$-terpinyl acetate $>$ terpinen-4-ol. The compound 1,8-cineole was the largest constituent in both oils, but $\beta$-caryophyllene (second and third most abundant compound in the leaves and fruit, respectively) exhibited the greatest toxicity using both methods. This compound had 15.25 and 92.25 fold greater toxicity in the fumigation assays than the essential oil from the leaves and fruit, respectively, as well as 250 and 214.23 fold greater toxicity in the residual contact assays than the essential oil from the leaves and fruit, respectively (Table III).

In the comparison of the toxicity of the pure compounds and the positive control, eugenol was the most toxic of all substances tested. The sesquiterpene $\beta$-caryophyllene, which exhibited the greatest toxicity of all constituents tested, was approximately 10 fold less toxic to $T$. urticae through fumigation than eugenol $\left(\mathrm{CL}_{50}=0.004 \mu \mathrm{L}\right.$ $\mathrm{L}^{-1}$ of air). However, $\beta$-caryophyllene was three fold more toxic than eugenol through residual contact.

Terpine-4-ol and $\alpha$-terpinyl acetate exhibited equal toxicity to that of the leaf oil through fumigation. The monoterpene 1,8-cineole exhibited equal toxicity to that of the fruit oil through fumigation. In the residual contact assays, the monoterpenes 1,8 -cineole and $\alpha$-terpinyl acetate exhibited equal toxicity to that of the leaf and fruit oils. These findings suggest that these constituents and especially $\beta$-caryophyllene are responsible 
TABLE III

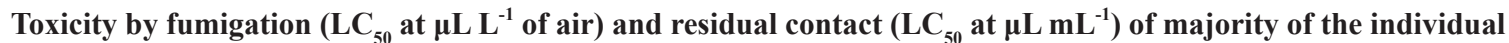
compounds selected from oils $V$. agnus-castus oils against Tetranychus urticae.

\begin{tabular}{|c|c|c|c|c|c|c|}
\hline Compound & $\mathbf{n}$ & df & $\begin{array}{c}\text { Slope } \\
\text { (CI 95\%) }\end{array}$ & $\begin{array}{c}\text { Fumigation } \\
\text { (CI 95\%) }\end{array}$ & $\chi^{2}$ & $\begin{array}{c}\mathrm{TR}_{50} \\
(\mathrm{CI} 95 \%) \\
\end{array}$ \\
\hline$\beta$-pinene & 630 & 4 & $\begin{array}{c}2.95 \\
(2.69-3.20)\end{array}$ & $\begin{array}{c}4.92 \\
(3.49-6.16) d\end{array}$ & 9.16 & $\begin{array}{c}110.03 \\
(59.96-201.92)\end{array}$ \\
\hline 1.8-cineole & 630 & 4 & $\begin{array}{c}8.16 \\
(7.62-8.22)\end{array}$ & $\begin{array}{c}4.34 \\
(3.95-4.73) \mathrm{d}\end{array}$ & 7.76 & $\begin{array}{c}97.10 \\
(60.06-156.99)\end{array}$ \\
\hline terpinen-4-ol & 450 & 3 & $\begin{array}{c}5.64 \\
(5.12-6.16)\end{array}$ & $\begin{array}{c}0.42 \\
(0.35-0.49) b\end{array}$ & 5.86 & $\begin{array}{c}9.51 \\
(8.30-10.91)\end{array}$ \\
\hline$\alpha$-terpineol & 633 & 4 & $\begin{array}{c}6.08 \\
(5.20-6.96)\end{array}$ & $\begin{array}{c}2.39 \\
(1.64-2.76) \mathrm{c}\end{array}$ & 7.81 & $\begin{array}{c}17.21 \\
(13.62-21.76)\end{array}$ \\
\hline$\alpha$-terpinyl acetate & 540 & 3 & $\begin{array}{c}10.23 \\
(9.45-11.01)\end{array}$ & $\begin{array}{c}0.50 \\
(0.48-0.51) \mathrm{b}\end{array}$ & 1.83 & $\begin{array}{c}11.19 \\
(9.39-13.34)\end{array}$ \\
\hline$\beta$-caryophyllene & 720 & 6 & $\begin{array}{c}0.80 \\
(0.33-1.27)\end{array}$ & $\begin{array}{c}0.04 \\
(0.02-0.07) \mathrm{a}\end{array}$ & 9.12 & - \\
\hline Compound & $\mathbf{n}$ & df & $\begin{array}{c}\text { Slope } \\
\text { (CI 95\%) }\end{array}$ & $\begin{array}{c}\text { Contact } \\
\text { (CI 95\%) }\end{array}$ & $\chi^{2}$ & $\begin{array}{c}\text { TR }_{50} \\
(\mathrm{CI} 95 \%)\end{array}$ \\
\hline$\beta$-pinene & 150 & 4 & $\begin{array}{c}2.73 \\
(2.39-3.07)\end{array}$ & $\begin{array}{c}38.93 \\
(31.72-46.91) \mathrm{b}\end{array}$ & 8.10 & $\begin{array}{c}61.49 \\
(3.63-1040.76)\end{array}$ \\
\hline terpinen-4-ol & 149 & 4 & $\begin{array}{c}9.47 \\
(7.96-10.98)\end{array}$ & $\begin{array}{c}366.56 \\
(306.47-421.30) \mathrm{e}\end{array}$ & 8.43 & $\begin{array}{c}603.33 \\
(72.99-4986.55)\end{array}$ \\
\hline$\alpha$ - terpineol & 123 & 3 & $\begin{array}{c}1.70 \\
(1.46-1.94)\end{array}$ & $\begin{array}{c}40.43 \\
(27.48-58.72) b\end{array}$ & 2.94 & $\begin{array}{c}63.29 \\
(3.54-1129.32)\end{array}$ \\
\hline 1,8-cineole & 150 & 3 & $\begin{array}{c}2.61 \\
(2.21-3.01)\end{array}$ & $\begin{array}{c}91.80 \\
(72.78-117.84) c\end{array}$ & 1.97 & $\begin{array}{c}144.86 \\
(9.31-2254.06)\end{array}$ \\
\hline$\alpha$-terpinyl acetate & 150 & 3 & $\begin{array}{c}3.80 \\
(3.15-4.45)\end{array}$ & $\begin{array}{c}151.54 \\
(129.54-179.85) \mathrm{d}\end{array}$ & 2.74 & $\begin{array}{c}238.25 \\
(17.99-3154.97)\end{array}$ \\
\hline$\beta$-caryophyllene & 175 & 5 & $\begin{array}{c}2.25 \\
(1.97-2.52)\end{array}$ & $\begin{array}{c}0.64 \\
(0.49-0.83) \mathrm{a}\end{array}$ & 0.72 & , \\
\hline
\end{tabular}

$\mathrm{n}=$ number of mites/dose; $\mathrm{df}=$ degrees of freedom. $\mathrm{CI}=$ confidence interval; $\chi^{2}=$ chi-squared; $\mathrm{TR}=$ toxicity ratio. $\mathrm{LC}_{50}$ with the same letter into the same column do not differ significantly by the confidence interval.

for the toxicity found in the essential oils from $V$. agnus-castus. However, the question remains regarding the point to which the toxicity of an essential oil can be attributed to an individual constituent or its percentage in the oil and whether other factors, such as synergic and antagonistic interactions among the different constituents and their proportional relationship in the oil, contribute to toxicity.

To investigate the role of the selected monoterpenes and sesquiterpenes from the oils of the leaves and fruit of $V$. agnus-castus L., the fumigation and residual contact bioassays were repeated with different blends of the major constituents, considering the same relative proportion at which these compounds were identified through GC-MS in the respective oils. Complete blends were first prepared with the selected chemical constituents of the oils from the fruit and leaves. The leaf artificial blend (LAB) was made up of $\beta$-pinene (5.6 $\pm 0.1 \%), 1,8$-cineole $(17.6 \pm 0.3 \%)$, terpinen-4-ol $(5.2 \pm 0.0 \%), \alpha$-terpineol (7.4 $\pm 0.0 \%) . \alpha$-terpinyl acetate $(8.3 \pm 0.0 \%)$ and $\beta$-caryophyllene $(9.4 \pm$ $0.0 \%$ ), representing a total of $53.5 \%$ of the oil. The fruit artificial blend (FAB) was made up of 1,8-cineole $(17.5 \pm 0.1 \%)$, terpinen-4-ol $(5.4 \pm 0.0 \%)$, 
$\alpha$-terpineol (5.2 $\pm 0.0 \%), \alpha$-terpinyl acetate $(11.9 \pm$ $0.1 \%)$ and $\beta$-caryophyllene $(6.1 \pm 0.0 \%)$, representing $46.1 \%$ of the oil. Other blends were prepared by removing one of the constituents and evaluated through fumigation and residual contact assays at the same concentration at which the respective oil achieved $\geq 95.0 \%$ mortality ( 15 and $12 \mu \mathrm{L} \mathrm{L}^{-1}$ of air for the fruit and leaf oils, respectively, in the fumigation assays and 400 and $350 \mu \mathrm{L} / \mathrm{mL}$ for the fruit and leaf oils, respectively, in the residual contact assays). The results obtained with the different blends were compared to the toxicity of the respective oils and positive control.

Based on the $\mathrm{CL}_{50}$ values for the complete blends of the constituents of the leaf and fruit oils, the artificial blends (LAB and FAB) exhibited the same degree of toxicity. This finding differs from the results of the essential oils from the fruit and leaves in the fumigation and residual contact assays, which differed significantly from each other. In comparison to eugenol, the toxicity of the artificial blends was 330 and 45 fold lesser in the fumigation and residual contact assays, respectively (Table IV).

Only toxicity through fumigation using the $\mathrm{LAB}\left(\mathrm{CL}_{50}=1.32 \mu \mathrm{L} \mathrm{L}^{-1}\right.$ of air) was approximately two fold lesser in comparison to the essential oil from the leaves. Toxicity through residual contact with the LAB and through both fumigation and contact with the FAB was greater in comparison to the oil from the fruit. The results suggest that the acaricidal activity through contract with the essential oil from the leaves and through both fumigation and contact with the essential oil from the fruit

TABLE IV

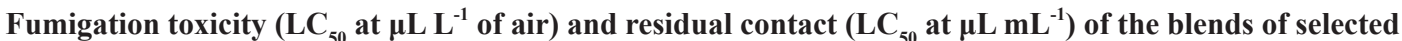
constituents and essential oils of leaves and fruits of Vitex agnus-castus $\mathrm{L}$.

\begin{tabular}{|c|c|c|c|c|c|c|c|}
\hline \multicolumn{2}{|c|}{ Treatment } & $\mathbf{n}$ & df & $\begin{array}{c}\text { Slope } \\
\text { (CI 95\%) }\end{array}$ & $\begin{array}{l}\text { Fumigation } \\
\text { (CI 95\%) }\end{array}$ & $\chi^{2}$ & $\begin{array}{c}\mathrm{TR}_{50} \\
(\mathrm{CI} 95 \%) \\
\end{array}$ \\
\hline \multirow{2}{*}{ AB } & Leaf & 540 & 3 & $\begin{array}{c}6.35 \\
(5.81-6.89)\end{array}$ & $\begin{array}{c}1.32 \\
(1.08-1.50) \mathrm{c}\end{array}$ & 7.57 & $\begin{array}{c}386.63 \\
(0.51-288755.62)\end{array}$ \\
\hline & Fruit & 450 & 2 & $\begin{array}{c}8.35 \\
(7.58-9.11)\end{array}$ & $\begin{array}{c}1.20 \\
(1.00-1.40) \mathrm{c}\end{array}$ & 4.04 & $\begin{array}{c}359.50 \\
(0.48-267577.40)\end{array}$ \\
\hline \multirow{2}{*}{ EO } & Leaf & 720 & 5 & $\begin{array}{c}1.30 \\
(1.21-1.39)\end{array}$ & $\begin{array}{c}0.61 \\
(0.38-0.92) b\end{array}$ & 8.48 & $\begin{array}{c}185.56 \\
(0.25-137638.30)\end{array}$ \\
\hline & Fruit & 720 & 4 & $\begin{array}{c}3.25 \\
(2.98-3.51)\end{array}$ & $\begin{array}{c}3.69 \\
(3.30-4.09) \mathrm{d}\end{array}$ & 1.35 & $\begin{array}{c}1125.00 \\
(1.49-846754.10)\end{array}$ \\
\hline \multirow[t]{2}{*}{$\mathbf{E U}$} & & 540 & 5 & $\begin{array}{c}0.85 \\
(0.77-0.92)\end{array}$ & $\begin{array}{c}0.004 \\
(0.002-0.005) \mathrm{a}\end{array}$ & 1.52 & - \\
\hline & & $\mathbf{n}$ & df & $\begin{array}{c}\text { Slope } \\
(\mathrm{CI} 95 \%) \\
\end{array}$ & $\begin{array}{c}\text { Contact } \\
(\text { CI 95\%) } \\
\end{array}$ & $\chi^{2}$ & $\begin{array}{c}\mathrm{TR}_{50} \\
(\mathrm{CI} 95 \%) \\
\end{array}$ \\
\hline \multirow{2}{*}{ AB } & Leaf & 125 & 6 & $\begin{array}{c}6.35 \\
(5.28-7.46)\end{array}$ & $\begin{array}{c}79.57 \\
(70.78-88.43) \mathrm{d}\end{array}$ & 1.26 & $\begin{array}{c}46.96 \\
(21.99-100.31)\end{array}$ \\
\hline & Fruit & 125 & 2 & $\begin{array}{c}5.29 \\
(4.31-6.27)\end{array}$ & $\begin{array}{c}77.18 \\
(59.50-97.55) \mathrm{d}\end{array}$ & 2.18 & $\begin{array}{c}41.59 \\
(17.65-98.01)\end{array}$ \\
\hline \multirow{2}{*}{ EO } & Leaf & 175 & 4 & $\begin{array}{c}2.45 \\
(2.10-2.81)\end{array}$ & $\begin{array}{c}160.48 \\
(101.25-271.67) \mathrm{e}\end{array}$ & 7.02 & $\begin{array}{c}82.75 \\
(31.03-220.69)\end{array}$ \\
\hline & Fruit & 175 & 4 & $\begin{array}{c}2.81 \\
(2.45-3.17)\end{array}$ & $\begin{array}{c}137.11 \\
(96.16-193.35) \mathrm{e}\end{array}$ & 4.85 & $\begin{array}{c}78.34 \\
(36.26-169.25)\end{array}$ \\
\hline $\mathbf{E U}$ & & 174 & 5 & $\begin{array}{c}2.16 \\
(1.85-2.47) \\
\end{array}$ & $\begin{array}{c}1.76 \\
(1.22-2.46) \mathrm{c}\end{array}$ & 5.59 & \\
\hline
\end{tabular}

$\mathrm{AB}=$ artificial mixture of constituents prepared at same percentage composition identified by GC/MS analyses of leaf and fruit oil. $\mathrm{EU}=$ Eugenol as positive control. $\mathrm{LC}_{50}$ with the same letter into the same column do not differ significantly by the confidence interval. 
can be attributed to the components selected for the LAB $[\beta$-pinene $(5.6 \pm 0.1 \%), 1,8$-cineole $(17.6$ $\pm 0.3 \%)$, terpinen-4-ol $(5.2 \pm 0.0 \%), \alpha$-terpineol $(7.4 \pm 0.0 \%), \alpha$-terpinyl acetate $(8.3 \pm 0.0 \%)$ and $\beta$-caryophyllene $(9.4 \pm 0.0 \%)]$ and FAB [1,8-cineole $(17.5 \pm 0.1 \%)$, terpinen-4-ol $(5.4 \pm 0.0 \%)$, $\alpha$-terpineol (5.2 $\pm 0.0 \%), \alpha$-terpinyl acetate $(11.9 \pm$ $0.1 \%)$ and $\beta$-caryophyllene $(6.1 \pm 0.0 \%)]$ at the proportions identified by GC-MS. The findings show that the preparation of blends of selected chemical constituents from an essential oil can cause interactions among components, either increasing (synergism) or diminishing (antagonism) the acaridical activity in comparison to the complete oil, but do not reveal the actual role of each constituent in the oil or previously prepared blends.

Figure 2 displays the mean mite mortality rates through fumigation and residual contact of the blends with the removal of one of the constituents from the complete blend of the leaf oil. For the fumigation bioassay, the removal of some constituents, such as 1,8 -cineole, $\beta$-pinene, $\alpha$-terpineol and terpinen-4-ol, did not affect the mortality rate, indicating that these components contribute practically nothing to the toxicity found in the complete blend. In contrast, the removal of $\alpha$-terpinyl acetate, which was the second most toxic $\left(\mathrm{CL}_{50}=0.50 \mu \mathrm{L} \mathrm{L}^{-1}\right.$ of air) among the constituents tested and the third most abundant constituent (8.3 $\pm 0.0 \%$ ) in the leaf oil, led to a drastic reduction in the mortality rate. Thus, the data suggest that the monoterpene $\alpha$-terpinyl acetate contributes most to toxicity through fumigation of the complete blend of the oil from the leaves of V. agnus-castus L.

Following the same line of reasoning, the analysis of toxicity from the partial blends during the residual contact assays suggests that 1,8 -cineole, $\alpha$-terpinyl acetate and $\beta$-caryophyllene contribute most to the acaricidal activity of the artificial leaf oil blend (Figure 2), with similar mortality rates for each component cited. These data suggest that these components contribute most to toxicity through re-

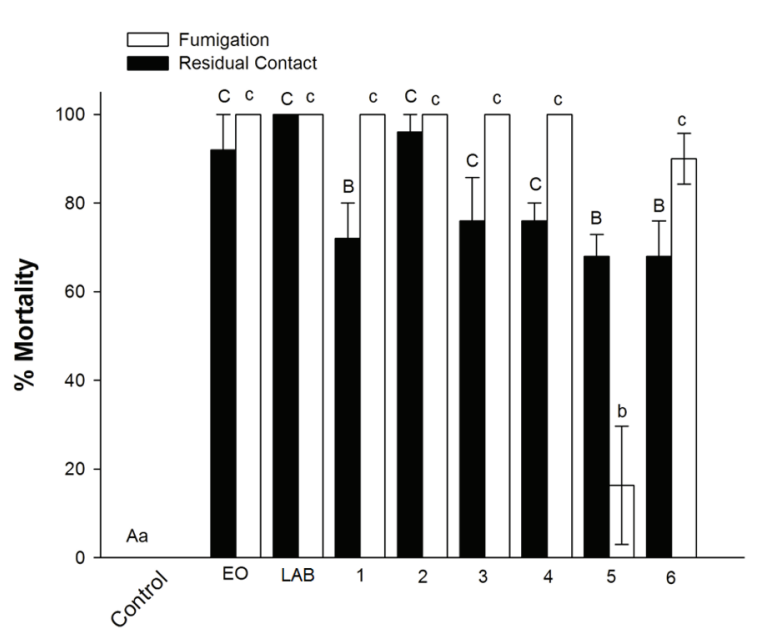

Figure 2 - Mean mortality of mite caused by the blend with the removal of one of the constituents from the complete blend of the leaf oil at concentration equivalent to the experiment with the leaf oil that promoted mortality $\geq 96.0 \%$ (12 $\mu \mathrm{L} / \mathrm{L}$ of air for fumigation and $350 \mu \mathrm{L} / \mathrm{mL}$ for residual contact). Bars with the same uppercase or lowercase not differ significantly by Tukey test $(\mathrm{P} \leq 0.05) . \mathrm{C}=$ control, $\mathrm{EO}=$ Essential oil from the leaves of $V$. agnus-castus, LAB $=$ Leaf Artificial Blend of the six compounds selected from the OE. The numbers indicate the blends with the absence of the labeled compound. $1=1,8$-cineole, $2=\beta$-pinene, $\alpha$-terpineol $3=4=$ terpinen-4-ol, $5=\alpha$-ethyl terpinila; $6=$ $\beta$-caryophyllene.

sidual contact of the complete blend of the oil from the leaves of $V$. agnus-castus L.

Figure 3 displays the results of the fumigation and residual contact bioassays with the partial blends prepared by the removal of one of the components from the complete blend of chemical constituents selected from the essential oil from the fruit. As found with the fumigation bioassay for the partial blends of the leaf oil, the removal of $\alpha$-terpinyl acetate led to a strong reduction in the mite mortality rate, whereas the removal of the other components did not significantly affect the mortality rate. Thus, $\alpha$-terpinyl acetate contributes most to the fumigant action of the blend of the fruit oil on the two-spotted spider mite. In the residual contact assays, mean mite mortality with the removal of $\alpha$-terpinyl acetate and 1,8-cineole did not differ significantly between the two partial 
blends and was greater than that found with the removal of terpinen-4-ol. Therefore, these constituents contribute most to the toxicity of the complete blend of the fruit oil through residual contact.

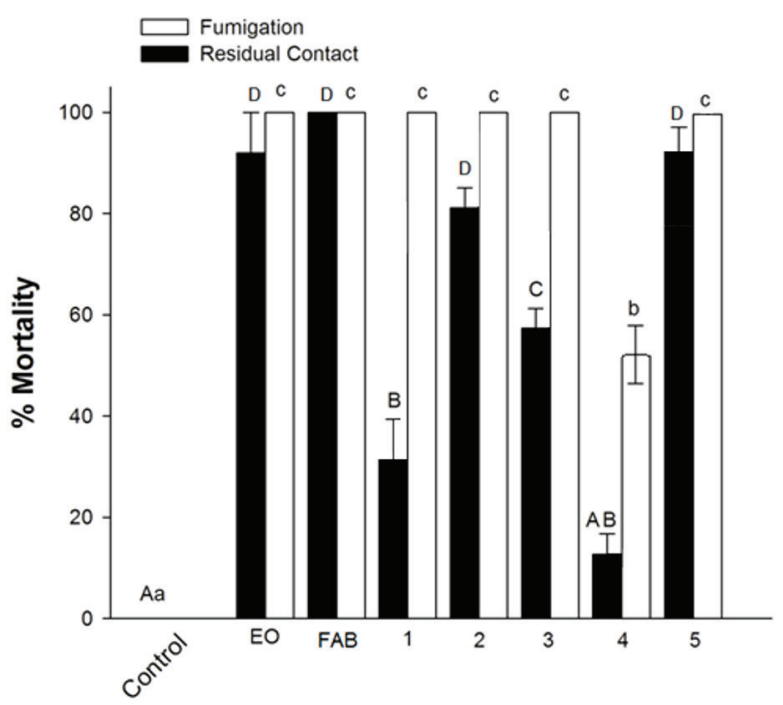

Figure 3 - Mean mortality of mites caused by the blend with the removal of one of the constituents from the complete blend of the fruit oil at concentration equivalent to the experiment with fruit oil that promoted mortality $\geq 96.0 \%(15 \mu \mathrm{L} / \mathrm{L}$ of air for fumigation and $400 \mu \mathrm{L} / \mathrm{mL}$ for residual contact). Bars with the same uppercase or lowercase same not differ significantly by Tukey test test $(\mathrm{P} \leq 0.05) . \mathrm{C}=$ control, $\mathrm{EO}=$ pure essential oil of fruits $V$. agnus castus, FAB = Fruits Artificial Blend of the five compounds selected from the EO. The numbers indicate the blends with the absence of the labeled compound. 1,8-cineole $1=2=\alpha$-terpineol, terpinen- $4=3$-ol, $4=\alpha$-acetate terpinila, $5=\beta$-caryophyllene.

Chemical investigation of essential oils of different part of the Vitex agnus-castus collected in the fragment of Atlantic forest of Pernambuco revealed two chemotypes, 1,8-cineole $\beta$-(E)-farnesene, also found in the North Region of Brazil. This data corroborate to the study reported by Andrade-Lima (1966), who found that many plant genera and species are common in both regions. The present findings on the acaricidal activity of essential oils from V.agnus-castus demonstrate that this property is related to both the individual properties of the chemical constituents as well as the proportion at which these compounds are found in the blend and their interactions.

According to the acaricidal activity demonstrated in this work by residual contact and fumigant bioassays associated with repellent property, the essential oil of Vitex agnus-castus seems to be a promising acaricide. However, further studies are needed to establish the cost-benefit ratio to be used as the active principle in the formulation for an integrated management of T. urticae.

\section{ACKNOWLEDGMENTS}

The first author is grateful for the research grants award by the Brazilian fostering agency Fundação de Amparo à Ciência e Tecnologia de Pernambuco FACEPE (Proc. N IBPG-0377-1.06/10). Grateful to Brazilian fostering agency Conselho Nacional de Desenvolvimento Científico e Tecnológico (CNPq/ Universal Proc. No 477778/2013-5) by financial support.

\section{REFERENCES}

ADAMS RP. 2007. In Identification of Essential Oil Components by Gas Chromatography/Quadrupole Mass Apectroscopy, $4^{\text {th }}$ ed., Allured Publishing Corporation: Carol Stream, 804 p.

ANDRADE-LIMA D. 1966. Contribuição ao estudo do paralelismo da flora amazônico-nordestina. Inst Agr Pernambuco, NS Bol Tec 19: 3-30.

ARAÚJO MJC, DA CAMARA CAG, BORN FS, MORAES MM AND BADJI CA. 2012. Acaricidal activity and repellency of essential oil from Piper aduncum and its components against Tetranychus urticae. Exp Appl Acarol 57: $139-155$.

DANIELE C, THOMPSON C, PITTLER M AND ERNST E. 2005. Vitex agnus-castus: A systematic review of adverse events. Drug Safety 28: 319-332.

DUYMUŞ HG, ÇIFTÇI GA, YILDIRIM ŞU, DEMIRCI B AND KIRIMER N. 2014. The cytotoxic activity of Vitex agnus castus L. essential oils and their biochemical mechanisms. Ind Crop Prod 55: 33-42.

ELGENGAIHI SE, MOTAWE HM, OMER EA AND ELBAZZA ZE. 1992. Chemical and biological studies on Vitex agnus-castus L. volatile oils. Indian Perfumer 36: 293-296. 
ERYIGITA T, ÇIGB A, OKUTC N, YILDIRIMD B AND EKICIE K. 2015. In vitro antimutagenic activity of Vitex agnus-castus L. essential oils and ethanolic extracts. J Essent Oil Bear P1 18: 208-214.

GALLETTI GC, RUSSO MT AND BOCCHINI P. 1996. Essential oil composition of leaves and berries of Vitex agnus-castus L. from Calabria, Southern Italy. Rapid Commun Mass Sp 10: 1345-1350.

HAMID AA, USMAN LA, ADEBAYO SA, ZUBAIR MF AND ELAIGWU SE. 2010. Constituents of leaf essential oil of North-central Nigerian grown Vitex agnus-castus L. Adv Environ Biol 4: 250-253.

LEORA S. 1987. POLO-PC: A User's Guide to Probit Logit Analysis; Berkely.

MALES Z, BLAZEVIC N AND ANTOLIC A. 1998. The essential oil composition of Vitex agnus-castus $\mathrm{f}$. rosea leaves and flowers. Planta Med 64: 286-287.

MARONGIU B, PIRAS A, PORCEDDA S, FALCONIERI D, GONCALVES MJ, SALGUEIRO L, MAXIAAAND LAI R. 2010. Extraction, separation and isolation of volatiles from Vitex agnus-castus L. (Verbenaceae) wild species of Sardinia, Italy, by supercritical $\mathrm{CO}_{2}$. Nat Prod Res Part A: Structure and Synthesis 24: 569-579.

MATOS FJA. 2002. Farmácias vivas: sistema de utilização de plantas medicinais projetado para pequenas comunidades. $4^{\mathrm{a}}$ ed., Fortaleza: Editora UFC, 267 p.

MIGUEL M, BOUCHMAAA N, AAZZA S, GAAMOUSSI F AND LYOUSSI B. 2014. Antioxidant, anti-inflammatory and anti-acetylcholinesterase activities of eleven extracts of Moroccan plants. Fresen Environ Bull 23: 1375-1388.

MORAES MM, DA CAMARA CAG, DOS SANTOS ML AND FAGG CW. 2012. Essential Oil Composition of Eugenia langsdorffii O. Berg.: Relationships between Some terpenoids and toxicity against Tetranychus urticae. J Brazil Chem Soc 23: 1647-1656.

MOUDACHIROU M, AYEDOUN MA, SOSSOU PV, GARNEAU FX, GAGNON H AND JEAN FI. 1998. Chemical composition of leaf oil of Vitex agnus-castus L. from Benin. J Essent Oil Res 10: 343-344.

NOVAK J, DRAXLER L, GOEHLER I AND FRANZ CM. 2005. Essential oil composition of Vitex agnus-castus comparison of accessions and different plant organs. Flavour Frag J 20: 186-192.

NTALLI NG, FERRARI F, GIANNAKOU I AND MENKISSOGLU-SPIROUDI U. 2010. Phytochemistry and nematicidal activity of the essential oils from 8 greek Lamiaceae aromatic plants and 13 terpene components. J Agric Food Chem 58: 7856-7863.
OMIKOREDE O, LAWAL OA AND IRESEMOWO AO. 2012. Volatile constituents, antibacterial and insecticidal activities of essential oil from the leaves of Vitex agnuscastus L. (Verbenaceae). Can J Comp Math Nat Sci Eng Med 3: 256-260.

PONTES WJT, OLIVEIRA JCS, DA CAMARA CAG, GONDIM-JUNIOR MGC, OLIVEIRA JV AND SCHWARTZ MOE. 2007b. Atividade acaricida dos óleos essenciais de folhas e frutos de xylopia sericea sobre o ácaro rajado (tetranychus urticae koch). Quim Nova 30: 838-841.

PONTES WJT, OLIVEIRA JCS, DA CAMARA CAG, LOPES ACHR, GONDIM-JUNIOR MGC, OLIVEIRA JV AND SCHWARTZ MOE. 2007a. Composition and acaricidal activity of the resins essential oil of $P$. bahianum Daly against two spotted spider mite (Tetranychus urticae). J Essent Oil Res 19: 379-383.

ROBERTSON JL AND PREISLER HK. 1992. Pesticide bioassays with arthropods. California, CRC Press, 127 p.

SARAC N, UGUR A AND SEN B. 2015. The cytotoxic activity of Vitex agnus-castus L. essential oils and their biochemical mechanisms. Ind Crop Prod 63: 100-103.

SARIKURKCU C, ARISOY K, TEPE B, CAKIR A, ABALI G AND METE E. 2009. Studies on the antioxidant activity of essential oil and different solvent extracts of Vitex agnus-castus L. fruits from turkey. Food Chem Toxicol 47: 2479-2483.

SAS INSTITUTE. 2002. SAS/User's Guide: Statistics, version 9.0, $7^{\text {th }}$ ed., SAS Institute Inc.: Cary.

SENATORE F, NAPOLITANO F AND OZCAN M. 2003. Chemical composition and activity of essential oil from fruits of Vitex agnus-castus L. (Verbenaceae) growing in Turkey. J Essent Oil Bear P1 6: 185-190.

SENATORE F, PORTA GD AND REVERCHON E. 1996. Constituents of Vitex-agnus-castus L. essential oil. Flavour Frag J 11: 179-182.

SORENSEN JM AND KATSIOTIS STH. 1999. Variation in essential oil yield and composition of Cretan Vitex agnuscastus L. fruits. J Essent Oil Res 11: 599-605.

STOJKOVIC D, SOKOVIC M, GLAMOCLIJA J, DZAMIC A, CIRIC A, RISTIC M AND GRUBISIC D. 2011. Chemical composition and antimicrobial activity of Vitex agnus-castus L. fruits and leaves essential oils. Food Chem 128: 1017-1022.

ZOGHBI MGB, ANDRADE EHA, SANTOS AS, SILVA MHL AND MAIA JGS. 1999. Essential oils of Vitex agnus-castus L. growing in the Amazon region. Flavour Frag J 14: 211-213. 